\title{
A 60-Year Literature Review on Hepatic Actinomycosis
}

\author{
Sofia Maraki ${ }^{a}$ Viktoria Eirini Mavromanolaki ${ }^{\mathrm{b}}$ Dimitra Stafylaki ${ }^{\mathrm{a}}$ \\ Eliza Anagnostopoulou ${ }^{c}$ Panagiotis Moraitis ${ }^{a} \quad$ Anna Kasimati $^{a}$ Boris Treptow ${ }^{c}$
}

aDepartment of Clinical Microbiology and Microbial Pathogenesis, University Hospital of Heraklion, Heraklion, Greece; bUniversity of Crete Medical School, Heraklion, Greece; 'Department of Surgical Oncology, University Hospital of Heraklion, Heraklion, Greece

\section{Highlights of the Study}

- Hepatic actinomycosis (HA) is a rare intra-abdominal infection accounting for $15 \%$ of cases of actinomycoses.

- HA is usually cryptogenic and is more common among males and in immunocompetent individuals.

- Diagnosis of HA is often difficult because of its indolent course and nonspecific clinical presentation and imaging findings.

- Treatment options include antimicrobial agents, drainage of the abscess, and surgical resection of the necrotic tissue.

\section{Keywords}

Hepatic actinomycosis · Liver abscess

\begin{abstract}
Hepatic actinomycosis $(\mathrm{HA})$ is a rare infection with an indolent course, atypical clinical manifestations, nonspecific laboratory and imaging findings, and challenging diagnosis. We describe a case of a 35-year-old female who developed HA 2 weeks after gastrectomy. In addition, we analyzed clinical characteristics and outcome of 157 additional cases of HA identified in a 60-year literature review. Patients with HA were predominantly male (57\%) and more than one-half were between 40 and 70 years of age. The infection was cryptogenic in $80.8 \%$ of cases. Risk factors for HA were identified in $63.1 \%$ of the patients. Clinical presentation included fever (57.7\%), abdominal pain (52.1\%), weight loss (45.1\%), anorexia (27.5\%), fatigue and chills (12.7\% each), and malaise (12\%) over a 2.35
\end{abstract}

Karger@karger.com www.karger.com/mpp

Karger $\stackrel{\text { ' }}{5}$
C) 2022 The Author(s).

Published by S. Karger AG, Basel

This is an Open Access article licensed under the Creative Commons Attribution-NonCommercial-4.0 International License (CC BY-NC) (http://www.karger.com/Services/OpenAccessLicense), applicable to the online version of the article only. Usage and distribution for commercial purposes requires written permission. \pm 3.5 months period. Leukocytosis, elevated alkaline phosphatase, erythrocyte sedimentation rate, and C-reactive protein were the most frequent laboratory findings. Radiologic imaging revealed that the right lobe was more frequently affected (62.5\%) with a single lesion found in two-thirds of cases. Diagnosis was achieved by histopathologic examination in $70.6 \%$ of cases. Cultures yielded Actinomyces in 45 instances, with $A$. israelii being the most frequent species. Less than one-half of the patients were treated only with antibiotics, while the others received combined medical and surgical treatment. The median duration of antibiotic therapy was 135 days. The presence of multiple lesions or solid tumor-like lesions (without liquefaction) was significantly associated with medical therapy alone. The outcome was favorable in most cases (94\%). Although rarely encountered, HA should be considered in patients with a chronic or subacute inflammatory process of the liver to promptly diagnose and treat.

(c) 2022 The Author(s).

Published by S. Karger AG, Basel 


\section{Introduction}

Actinomycosis is a chronic suppurative, granulomatous infection caused by non spore-forming, filamentous, anaerobic Gram-positive bacteria of the genus Actinomyces. These microorganisms are part of the commensal flora of the oropharynx and the gastrointestinal and the female genital tract. Disruption of the mucosa may lead to infection. Among pathogenic species, Actinomyces israelii predominates in human infections [1]. Cervicofacial, thoracic, and abdominal actinomycoses are the most frequent clinical forms of the infection in humans. Liver involvement is rare accounting for $15 \%$ of the cases of abdominal actinomycosis. The diagnosis of hepatic actinomycosis (HA) is difficult and is often delayed because of its indolent course and the nonspecific clinical and radiological findings $[1,2]$. The preoperative rate of diagnosis is less than $10 \%$ [3]. Regarding actinomycosis, Cope [4] states that there is "no disease which is so often missed by expert clinicians." A case of HA in a patient who had undergone gastrectomy is presented here, with a review of all reported cases over the last 60 years.

\section{Case Report}

A 35-year-old woman was admitted to the General Hospital of Rethymno, Greece, with a 5-day history of fever up to $38.3^{\circ} \mathrm{C}$, chills, and diarrhea. She had a history of a laparoscopic sleeve gastrectomy 2 weeks earlier.

CT scan of the chest and abdomen revealed a hypodense cystic lesion of $10 \times 5.5 \mathrm{~cm}$ on the right lobe of the liver suggestive of pyogenic abscess and a small amount of right pleural effusion. The patient was started on piperacillin-tazobactam ( $4.5 \mathrm{~g}$ every $8 \mathrm{~h}$ i.v.) and metronidazole (500 mg every $8 \mathrm{~h}$ i.v.) and was transferred to the University Hospital of Heraklion. On admission, laboratory tests showed a leukocytosis of $16.1 \times 10^{9} / \mathrm{L}$ (neutrophils $83 \%$ ), mild anemia (hemoglobin $10.0 \mathrm{~g} / \mathrm{dL}$ ), elevated gamma-glutamyltransferase level (66 IU/L; normal: $<38 \mathrm{IU} / \mathrm{L}$ ), and elevated C-reactive protein level of $13.29 \mathrm{mg} / \mathrm{dL}$ (normal: $<0.5 \mathrm{mg} / \mathrm{dL}$ ). The rest of the tests were normal. On the same day, the patient underwent ultrasound-guided therapeutic and diagnostic aspiration of the liver abscess (Fig. 1). Pus from the abscess cavity was drained through a pigtail catheter, and the pus was sent for microbiological analysis. Gram stain revealed Gram-positive branching filamentous rods consistent with Actinomyces species. Anaerobic cultures yielded pure growth of Actinomyces odontolyticus that was identified using Vitek 2. Identification was further confirmed by matrix-assisted laser desorption/ionization time of flight mass spectrometry (MALDI-TOF MS), as well as by $16 \mathrm{~S}$ rRNA gene sequencing analysis. Antimicrobial susceptibility testing was performed by the Etest method, and the results were interpreted according to the Clinical and Laboratory Standards Institute (CLSI) guidelines. The organism was susceptible to penicillin, ampicillin, amoxicillin/clavulanate, piperacillin/tazobactam, cefoxitin, imipenem, merope-

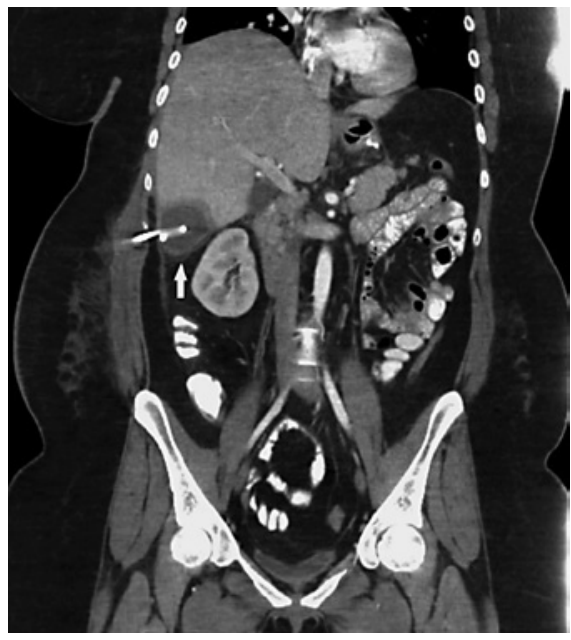

Fig. 1. Coronal contrast-enhanced CT image demonstrating the hepatic lesion in the right lobe with a drainage catheter in place (arrow).

nem, moxifloxacin, tigecycline, tetracycline, chloramphenicol, and vancomycin and resistant to metronidazole and clindamycin. Once antimicrobial susceptibilities were available, the antibiotics were switched to cefoxitin ( 1 g every $6 \mathrm{~h}$ ). The amount of drainage from the pigtail decreased over the following days, and the catheter was removed after 31 days of use. Follow-up abdominal sonography on days 6 and 11 after pus drainage showed progressive shrinkage of the abscess with sizes of $5.7 \times 4.9 \mathrm{~cm}$ and $4.7 \times 2.4 \mathrm{~cm}$. After discharge, amoxicillin-clavulanic acid ( $1 \mathrm{~g}$ every $12 \mathrm{~h}$ ) was prescribed. A follow-up abdominal CT performed 8 months after discharge showed the complete resolution of the infection.

\section{Review of the Literature}

We conducted a search (using the PubMed/MEDLINE, Scopus, and ScienceDirect databases) of the medical literature from January 1960 to July 2021, using the following keywords "Hepatic actinomycosis," OR "liver actinomycosis." We also included additional cases identified in the references of the cited papers. Articles written in English, Spanish, French, and German were included. We found 157 additional cases, and the following variables were recorded: patients' demographics, comorbidities, clinical symptoms, radiological characteristics, laboratory findings, causative agent and co-pathogens, method of diagnosis, treatment, and outcome. Percentages were calculated based on the actual number of patients with available data.

Three-quarters of the cases of HA have been reported in the last 30 years. Table 1 summarizes the patients' demographics and their comorbidities. Ninety patients 
Table 1. Characteristics of the 158 patients with hepatic actinomycosis

\begin{tabular}{lll}
\hline Age $($ mean \pm SD) & $49.3 \pm 18.1$ & Range, 4-88 \\
Gender (M/F) & $90 / 68$ & $57 \% / 43 \%$ \\
Comorbidities & $99^{\mathrm{a}}$ & $63.1 \%$ \\
$\quad$ Remote abdominal/pelvic surgery & 32 & $32.3 \%$ \\
$\quad$ Diabetes mellitus & 20 & $20.2 \%$ \\
Alcohol abuse & 14 & $14.1 \%$ \\
Dental caries/abscesses & 13 & $13.1 \%$ \\
IUCD & 11 & $11.1 \%$ \\
Viral hepatitis & 5 & $5.1 \%$ \\
Chololithiasis/cholangitis & 4 & $4.0 \%$ \\
Illicit drugs & 3 & $3.0 \%$ \\
End-stage renal disease-in hemodialysis & 2 & $2.0 \%$ \\
Miscellaneous & 12 & $12.1 \%$ \\
\hline
\end{tabular}

${ }^{\text {a }}$ Most of the patients had more than one comorbidities. " Miscellaneous: chronic pancreatitis $(n=2)$, hepatic insufficiency $(n=1)$, squamous cell carcinoma of the throat $(n=1)$, rectal adenocarcinoma $(n=1)$, sigmoid colon neoplasm $(n=1)$, corticosteroid treatment $(n=4)$, and immunosuppressive medication $(n=2)$.
(57\%) were males and 68 (43\%) were females. The mean age of patients with HA was $49 \pm 18.6$ years (range, $4-88$ years). Among the $158 \mathrm{HA}$ patients, only 8 were pediatric cases [5-12]. The disease had a worldwide distribution with most cases being reported in Asian countries (36.7\%). European and North American countries ranked second and third with $28.5 \%$ and $27.8 \%$ of cases, respectively.

Predisposing factors for HA were identified in 99 patients (63.1\%). Most patients had more than one comorbidity. In particular, remote surgical abdominal or pelvic procedures were described in $32.3 \%$ of patients $[3,13-$ 41 ]. Recent abdominal or pelvic surgery ( $\leq 1$ year) was reported in 25 cases including intrauterine contraceptive device (IUCD) removal $(n=12)$ [42-53], appendectomy $(n=3)$ [54-56], gastrectomy $(n=2)$ [57, present case], cholecystectomy $(n=3)[34,37,58]$, total pancreatectomy [59], stenting bile and pancreas $(n=2)[29,60]$, perforated peptic ulcer $(n=1)$ [61], and drainage of a rectal abscess $(n=1)$ [62]. Other predisposing conditions included diabetes mellitus, alcohol abuse, dental caries or abscesses, the use of IUCD, viral hepatitis, chololithiasis and cholangitis, the use of illicit drugs, and end-stage renal disease-in hemodialysis. Most patients (94.9\%) were immunocompetent. Only 8 patients had underlying immunosuppressive conditions, including hemodialysis $(n=2)[21,63]$, on corticosteroids $(n=4)[17,64-66]$, or other immunosuppressive drugs $(n=2)$ (tacrolimus, hydroxychloroquine) $[3,40]$. The infection was cryptogenic and considered as primary in $80.8 \%$ of the patients, while in $19(12.2 \%), 10(6.4 \%)$, and $1(0.6 \%)$ was secondary to pelvic, abdominal, and pulmonary actinomycosis, respectively.

Hepatic Actinomycosis
Table 2. Radiological and anatomic characteristics of hepatic actinomycosis

\begin{tabular}{ll}
\hline Characteristic (patients, $n$ ) & $N(\%)$ \\
\hline $\begin{array}{l}\text { Type of lesion (139) } \\
\text { Cystic/abscess-like }\end{array}$ \\
$\quad$ Solid/tumor-like & $78(56.1)$ \\
Lesions, $n(152)$ & $61(43.9)$ \\
$\quad$ Single & $102(67.1)$ \\
$\quad$ Multiple & $50(32.9)$ \\
Location (152) & \\
Right lobe & $95(62.5)$ \\
Left lobe & $32(21.1)$ \\
Both & $25(16.4)$ \\
\hline
\end{tabular}

Fever was the most frequent presenting symptom in $82 / 142$ cases $(57.7 \%)$. The mean \pm SD temperature was $38.6^{\circ} \mathrm{C} \pm 1.03^{\circ} \mathrm{C}$ (range; $36.5^{\circ} \mathrm{C}-41^{\circ} \mathrm{C}$ ). Other symptoms were abdominal pain in $52.1 \%$ of the patients, weight loss in $45.1 \%$, anorexia in $27.5 \%$, chills in $12.7 \%$, fatigue in $12.7 \%$, malaise in $12 \%$, night sweats in $10.6 \%$, vomiting in $7.7 \%$, nausea in $4.9 \%$, diarrhea in $4.2 \%$, headache in $2.8 \%$, and myalgias in $1.4 \%$ of them. The onset of symptoms was mainly subacute, with a mean \pm SD duration of symptoms of $2.35 \pm 3.5$ months (range, 4 days -2 years). Acute presentation of symptoms ( $\leq 2$ weeks duration) was observed in only 31 cases $(24.6 \%)[6,11,22,23,27,28,31$, $41,47,65,67-85$, and the present case].

Findings on physical examination included right upper quadrant tenderness in $49 / 100$ cases (49\%), fever in $36 / 100$ cases $(36 \%)$, hepatomegaly in $30 / 100$ cases $(30 \%)$, 
Table 3. Diagnosis of hepatic actinomycosis

\begin{tabular}{ll}
\hline Technique-diagnostic method & Cases, $n(\%)$ \\
\hline Surgical drainage & $13(8.4)$ \\
Histopathology & $11(7.1)$ \\
Culture & $2(1.3)$ \\
Percutaneous drainage & $41(26.5)$ \\
Histopathology & $12(7.8)$ \\
Culture & $25(16.8)$ \\
Culture + blood culture & $3(1.9)$ \\
Surgical biopsy & $34(21.9)$ \\
Histopathology & $26(16.8)$ \\
Culture & $7(4.5)$ \\
PCR & $1(0.6)$ \\
Surgical resection & $26(16.8)$ \\
Histopathology & $23(14.9)$ \\
Culture & $3(1.9)$ \\
Percutaneous biopsy & $34(21.9)$ \\
Histopathology & $33(21.3)$ \\
Culture & $1(0.6)$ \\
Blood culture & $3(1.9)$ \\
Autopsy & $4(2.6)$ \\
\hline
\end{tabular}

an abdominal mass in $22 / 100$ cases $(22 \%)$, cachexia in $7 / 100(7 \%)$, dental caries/periodontal disease in $7 / 100$ cases $(7 \%)$, and jaundice in $6 / 100(6 \%)$. Laboratory tests revealed leukocytosis with a left shift in $85.3 \%$ of cases. The mean \pm SD leukocyte count was $16.9 \pm 7.5 \times 10^{9} / \mathrm{L}$ (range 5.0-47.0 $\times 10^{9} / \mathrm{L}$ ). Elevated erythrocyte sedimentation rate and $\mathrm{C}$-reactive protein levels were found in all reported cases ( 31 and 42 cases, respectively). Elevated alkaline phosphatase was found in $79.4 \%$ of cases. Aspartate aminotransferase was reported in 61 cases and was found elevated in 15 cases and slightly elevated in 4 . Alanine aminotransferase was reported in 63 cases and was found elevated in 12 cases and slightly elevated in 7 . Elevated bilirubin or jaundice was found in 11 cases of the 37 reported $[11,28,38,43,62,69-73,86]$.

Diagnostic radiologic imaging was performed by abdominal ultrasound and CT scan, while magnetic resonance imaging was performed in a small number of cases. The type of lesions included cystic/abscess-like appearance in almost two-thirds of cases, and in the rest, imaging demonstrated a mass, frequently misdiagnosed as primary or metastatic liver cancer. A single lesion was found in $67.1 \%$ of patients, and the right lobe was the most commonly affected (62.5\%) (Table 2). The infection extended to the surrounding tissues in 78 cases: diaphragm $(n=20)$, abdominal wall $(n=19)$, lung $(n=$ $17)$, pleura $(n=8)$, colon $(n=5)$, stomach $(n=3)$, gallbladder $(n=2)$, pancreas $(n=2)$, and kidney $(n=2)$.
Table 4. Actinomyces species isolated and co-isolates in mixed infections

\begin{tabular}{ll}
\hline Microorganisms & $n(\%)$ \\
\hline Actinomyces species $(n=32)$ & \\
A. israelii & $17(53.2)$ \\
A. meyeri & $4(12.5)$ \\
A. odontolyticus & $4(12.5)$ \\
A. naeslundii & $4(12.5)$ \\
A. turicensis & $1(3.1)$ \\
A. cardiffensis & $1(3.1)$ \\
A. bovis & $1(3.1)$ \\
Anaerobes ( $n=21)$ & \\
Fusobacterium spp. & $7(33.3)$ \\
Bacteroides spp. & $4(19)$ \\
Prevotella oris & $1(4.8)$ \\
Peptostreptococcus spp. & $3(14.3)$ \\
Eubacterium lentum & $1(4.8)$ \\
Propionibacterium acnes & $1(4.8)$ \\
Mixed anaerobic flora & $4(19)$ \\
Aerobic Gram-negative bacilli $(n=9)$ & \\
Pseudomonas aeruginosa & $2(22.2)$ \\
Proteus mirabilis & $1(11.1)$ \\
E. coli & $1(11.1)$ \\
Klebsiella pneumoniae & $1(11.1)$ \\
Haemophilus parainfluenzae & $1(11.1)$ \\
Capnocytophaga spp. & $2(22.2)$ \\
Eikenella corrodens & $1(11.1)$ \\
Gram-positive aerobic bacteria $(n=13)$ & \\
Streptococcus spp. & $6(46.2)$ \\
Enterococcus spp. & $3(23.1)$ \\
S. aureus & $1(7.7)$ \\
S. epidermidis & $1(7.7)$ \\
Abiotrophia spp. & $1(7.7)$ \\
Corynebacterium spp. & $1(7.7)$ \\
Yeasts $(n=3)$ & $3(100)$ \\
Candida spp. & \\
\hline & \\
& \\
\hline
\end{tabular}

Fistulas to the skin (through the abdominal wall), the bronchial tree, the lung, and the pericardial space were described in a limited number of cases $[9,13,39,62,87]$. Rare complications included thrombosis or obstruction of the portal vein $(n=8)[29,43,45,88-91]$, hepatic vein thrombosis $(n=3)[23,49,80]$ and inferior vena cava thrombosis or obstruction $(n=2)[23,81]$, cardiac tamponade $(n=3)[28,92,93]$, and gastrointestinal bleed $(n=1)$ [94].

Diagnosis was confirmed by histopathologic examination of surgical samples in 60 cases: biopsy $(n=26)$, drainage $(n=11)$, and resection $(n=23)$ or percutaneous samples $(n=45)$ : biopsy $(n=33)$ and drainage $(n=12)$. Diagnosis was confirmed by postmortem examination of the liver tissue in 4 cases $[69,89,93,95]$. Cultures of surgical and percutaneous specimens yielded Actinomyces 
Table 5. Univariate analysis of clinical and radiological characteristics associated with management of patients with hepatic actinomycosis

\begin{tabular}{lllc}
\hline Variable & $\begin{array}{l}\text { Surgical or percutaneous } \\
\text { drainage }\end{array}$ & $\begin{array}{l}\text { Medical therapy } \\
\text { alone }\end{array}$ & $p$ value \\
\hline Age in years (mean, range) & $48(4-82)$ & $50(6-82)$ & 0.69 \\
Male sex, $n / n(\%)$ & $32 / 69(46)$ & $37 / 69(53)$ & 0.49 \\
Comorbidities, $n / n(\%)$ & $36 / 83(43)$ & $47 / 83(57)$ & 0.1 \\
Cystic lesions, $n / n(\%)$ & $37 / 65(57)$ & $28 / 65(43)$ & 0.1 \\
Solid tumor-like lesions, $n / n(\%)$ & $9 / 35(25)$ & $26 / 35(75)$ & $<0.0001$ \\
Single lesion, $n / n(\%)$ & $36 / 70(48)$ & $34 / 70(51)$ & 0.8 \\
Multiple lesions, $n / n(\%)$ & $13 / 39(33)$ & $26 / 39(66)$ & 0.0062 \\
\hline
\end{tabular}

Continuous variables were analyzed by two-sided $t$ test. $p<0.05$ was considered statistically significant. All other analyses were performed with Fisher's exact test.

species in 12 and 27 instances, respectively. Diagnosis was confirmed by blood cultures in 3 cases $[70,96,97]$ and by culture of both blood and percutaneous drainage sample in 3 other cases $[71,74,77]$ (Table 3 ). Identification to the species level was performed in 32 cases, using either conventional methods, or the API system, the automated VITEK 2 system, MALDI-TOF MS, and 16S rRNA sequencing analysis. Genomic polymerase chain reaction (PCR) analysis was performed in 7 instances $[28,63,71,75,80$, 97 , and the present case]. A. israelii was the most frequently isolated species (Table 4). The infection was mixed in 32 cases, and the isolated co-pathogens are shown in Table 4.

Therapy involved antibiotic administration alone $(n=$ $62)$, combined antibiotic treatment and surgical drainage $(n=21)$, combined antibiotic treatment and percutaneous drainage $(n=31)$, combined antibiotic treatment and liver lobe resection $(n=31)$, and surgery alone $(n=$ 4). The median duration of antibiotic therapy was 135 days (range: 7-730 days). The most frequently administered antibiotics were intravenous penicillin $\mathrm{G}(60.8 \%)$, followed by long-term oral penicillin (26.9\%), amoxicillin (19.2\%), doxycycline (6.2\%), amoxicillin-clavulanic acid $(4.6 \%)$, or clindamycin (3.8\%). Importantly, univariate analysis demonstrated that the presence of multiple lesions or solid tumor-like lesions was significantly associated with medical therapy alone without the need for surgical intervention (Table 5). The majority of patients (94\%) responded well to treatment. The mortality rate in relation to types of treatment is presented in Table 6 . Mortality was not significantly different $(p=1.0)$ between those who received combined antibiotic treatment and surgical drainage and those treated with antibiotics alone.

Hepatic Actinomycosis
Table 6. Type of therapy and mortality rate

\begin{tabular}{lll}
\hline Type of therapy & $\begin{array}{l}\text { Patients, } \\
n\end{array}$ & $\begin{array}{l}\text { Mortality rate, } \\
n(\%)\end{array}$ \\
\hline Antibiotics alone & 62 & $4(6.5)$ \\
Antibiotics + hepatectomy & 31 & $0(0)$ \\
Antibiotics + surgical drainage & 21 & $1(4.8)$ \\
Antibiotics + percutaneous drainage & 31 & $0(0)$ \\
Resection & 4 & $0(0)$ \\
All cases & 150 & $9(6)$
\end{tabular}

Data on the type of treatment of 8 patients are missing.

\section{Discussion}

Human actinomycosis was first recognized in 1878 by Israel, who also later identified the microorganism's cultural characteristics and its anaerobic nature. Actinomycosis has been a common infection in the pre-antibiotic era, but its incidence has decreased with the advent of antibiotics. However, actinomycosis continues to be a problem in developing countries due to the low socioeconomic status and the limited access to medical therapy. Liver involvement is rare, accounting for only $5 \%$ of all cases of actinomycosis $[1,2]$. Only sporadic cases and case series of HA have been reported. The present review revealed the global distribution of the disease with its burden being higher in Asia, as recently reported [98]. A male predominance (3:2.3) was observed, and most patients were immunocompetent. The peak incidence of the disease is reported to be in the fourth decade of life, with cases being less frequent in children and elderly aged 80 years and above. 
Liver involvement may occur via extension from a contiguous abdominal focus or by hematogenous spread via the portal vein following mucosal injury induced by surgical or endoscopic manipulations, ulcer, foreign bodies, intra-abdominal infection, or immunosuppression $[1,2]$. One or more comorbidities were observed in more than half of the cases reviewed, with remote abdominal and pelvic surgery and diabetes mellitus being the most common. Nevertheless, most of the cases $(80.8 \%)$ were cryptogenic.

Symptoms of HA are variable, nonspecific, and indolent with most common manifestations being fever, abdominal pain, weight loss, and anorexia. Laboratory findings include leukocytosis with a left shift, erythrocyte sedimentation rate, C-reactive protein, and alkaline phosphatase elevations. Imaging features are also nonspecific and often mimic primary or metastatic neoplasms $[19,25,27,33,35,39,40,60,80,84,85]$.

Demonstration of aggregates of filamentous Grampositive organisms in "sulfur granules" of biopsy specimens or aspirated pus is suggestive of actinomycosis. The isolation in culture of Actinomyces species confirms the diagnosis. However, in a notable percentage of cases, cultures did not yield the causative microorganism. This is due either to previous antimicrobial treatment or to inhibition of growth by other microorganisms, and to inadequate culture conditions and short incubation period of culture specimens. Suitable and adequate sampling, handling, and processing of the samples is necessary for diagnosis. MALDI-TOF provides quick and accurate identification to the genus level, while $16 \mathrm{~S}$ rRNA sequencing is the reference method for definitive identification. PCR can also be used for direct detection of the microorganism in clinical specimens [2]. A. israelii was the predominant species, while A. odontolyticus, the species isolated from the aspirated pus of our patient, is relatively rare $[51,74,75]$. Other bacterial species were concomitantly isolated in many studies; these "companion microbes" serve as co-pathogens contributing to the inhibition of host immune responses and reducing the oxygen tension $[1,2]$.

Therapeutic options include antibiotics, drainage of the abscess, and resection of the necrotic tissue. Treatment of the infection with prolonged courses of antibiotics is recommended, to avoid recurrence [2]. Actinomyces are susceptible in vitro to many antibiotics. Penicillin $G$ is the drug of choice and must be given intravenously for 4-6 weeks, followed by oral penicillin $V$ for 6-12 months. Tetracyclines, doxycycline, erythromycin, and cephalosporins are effective alternatives [2]. In case of the pres- ence of co-pathogens, antimicrobial treatment should include coverage of these organisms. In our case, treatment included drainage of the abscess combined with intravenous therapy, followed by a maintenance oral therapy. Of interest, the presence of multiple lesions and solid lesions (without evidence of liquefaction) was significantly associated with conservative management without the need for surgical intervention. The more advanced cases require combined medical therapy and drainage of the abscess or surgical resection of the necrotic tissue for optimal outcome. However, despite the delayed diagnosis, the outcome of HA was excellent in most cases, with a mortality rate of $6 \%$.

HA, although rarely encountered, should be considered in the differential diagnosis of patients with chronic constitutional symptoms and evidence of solitary or multiple hypodense liver lesions and laboratory findings of chronic inflammation. Diagnosis is established by histological examination and cultures or PCR of the exudate and the biopsy or the surgical specimen. Medical therapy alone or combined with surgery has proven to be highly effective for management of this infection.

\section{Statement of Ethics}

Written informed consent was obtained from the patient for publication of this case report and accompanying images.

\section{Conflict of Interest Statement}

The authors have no conflicts of interest to declare.

\section{Funding Sources}

The authors did not receive any funding for this study.

References

1 Russo TA. Agents of actinomycosis. In: Bennett JE, Dolin R, Blaser MJ, editors. Mandell, douglas, and bennett's principles and practice of infectious diseases. Philadelphia, PA: Elsevier Saunders; 2015. p. 2864-73.

2 Valour F, Sénéchal A, Dupieux C, Karsenty J, Lustig S, Breton P, et al. Actinomycosis: etiology, clinical features, diagnosis, treatment, and management. Infect Drug Resist. 2014;7: 183-97.

3 Lall T, Shehab TM, Valenstein P. Isolated hepatic actinomycosis: a case report. J Med Case Rep. 2010;4:45.

4 Cope VZ. Visceral actinomycosis. Br Med J. 1949;2:1311-6. 
5 Rabusin M, D’Andrea N, Brizzi F, Bussani R, Ventura A. Primary hepatic actinomycosis. Pediatr Infect Dis J. 1996;15:382-4.

6 Guven A, Kesik V, Deveci MS, Ugurel MS, Ozturk H, Koseoglu V. Post varicella hepatic actinomycosis in a 5-year-old girl mimicking acute abdomen. Eur J Pediatr. 2008; 167: 1199-201.

7 Lin TP, Fu LS, Peng HC, Lee T, Chen JT, Chi CS. Intra-abdominal actinomycosis with hepatic pseudotumor and xanthogranulomatous pyelonephritis in a 6-year-old boy. Scand J Infect Dis. 2001;33:551-3.

8 Shah HR, Williamson MR, Boyd CM, Balachandran S, Angtuaco TL, McConnell JR. CT findings in abdominal actinomycosis. J Comput Assist Tomogr. 1987;11:466-9.

9 Buyukavci M, Caner I, Eren S, Aktas O, Akdag R. A childhood case of primary hepatic actinomycosis presenting with cutaneous fistula. Scand J Infect Dis. 2004;36:62-3.

10 Lunia S, Chodos RB, Sundaresh R. Actinomycosis of the liver and $67 \mathrm{Ga}$ citrate scintigraphy. Clin Nucl Med. 1976;1(7):263-4.

11 Heneghan HM, Healy NA, Martin ST, Ryan RS, Nolan N, Traynor O, et al. Modern management of pyogenic hepatic abscess: a case series and review of the literature. BMC Res Notes. 2011;4:80.

12 Liang ZJ, Liang JK, Chen YP, Chen Z, Wang $Y$. Primary liver actinomycosis in a pediatric patient: a case report and literature review. World J Clin Cases. 2021;9(20):5717-23.

13 Esposti D, Lippolis A, Cipolla M, Bonazzi M. An uncommon cause of pericardial actinomycosis. Ital Heart J. 2000;1:632-5.

14 Alawainati M, Al-Khawaja S, Shawqi Z, Alshaikh S. Disseminated actinomycosis a rare cause of abdominal pain: a case report. Oman Med J. 2020;35:e117.

15 Foreman JM. Actinomycosis of the liver. $\mathrm{N} Z$ Med J. 1963;62:536-7.

16 Goldberg ND, Anthony WC, Yen MC, Hashmi S. Hepatic actinomycosis. Md Med J. 1989; 38:751-2.

17 Oe S, Shibata M, Hiura M, Mitsuoka H, Matsuhashi T, Narita R, et al. Refractory primary hepatic actinomycosis with direct infiltration to the diaphragm and thorax: the usefulness of contrast-enhanced ultrasonography. Intern Med. 2014;53:2073-8.

18 Prioleau PG, Brochu FL. Penicillin and épluchage treatment of hepatic actinomycosis. Arch Surg. 1974;109:426-9.

19 Wayne MG, Narang R, Chauhdry A, Steele J. Hepatic actinomycosis mimicking an isolated tumor recurrence. World J Surg Oncol. 2011; 9:70.

20 Morrow JD, Neuzil KM. Primary hepatic actinomycosis: diagnosis by percutaneous transhepatic needle aspiration. J Tenn Med Assoc. 1993;86:99-101.

21 Cirino CM, Paal E, Gibert CL. An elderly man receiving hemodialysis who had diarrhea, weight loss, and liver mass. Clin Infect Dis. 2007;44:269306-9.
22 Tambay R, Côté J, Bourgault AM, Villeneuve JP. An unusual case of hepatic abscess. Can J Gastroenterol. 2001;15:615-7.

23 Wong JJ, Kinney TB, Miller FJ, Rivera-Sanfeliz G. Hepatic actinomycotic abscesses: diagnosis and management. Am J Roentgenol. 2006;186:174-6.

24 Grossen A, Magguilli M, Thai TC, Salem G. Hepatic actinomycosis in a patient with retained common bile duct stent. ACG Case Rep J. 2019;6:e00219.

25 Nozawa Y, Takamura M, Kamimura $\mathrm{H}$, Tsuchiya A, Terai S. A case of primary hepatic actinomycosis difficult to distinguish from malignant hepatic tumors. Kanzo. 2020;61: 109-15.

26 Castellón Pavón CJ, Foruria Franco AM, González Núñez MA, Morales Artero S, Martínez Sapiña A, del Amo Olea E. Actinomicosis hepática primaria Primary hepatic actinomycosis. Gastroenterol Hepatol. 2004;27: 464-6.

27 Kanellopoulou T, Alexopoulou A, Tiniakos D, Koskinas J, Archimandritis AJ. Primary hepatic actinomycosis mimicking metastatic liver tumor. J Clin Gastroenterol. 2010;44: 458-9.

28 Llenas-García J, Lalueza-Blanco A, Fernández-Ruiz M, Villar-Silva J, Ochoa M, Lozano F, et al. Primary hepatic actinomycosis presenting as purulent pericarditis with cardiac tamponade. Infection. 2012;40:339-41.

29 Harsch IA, Benninger J, Niedobitek G, Schindler G, Schneider HT, Hahn EG, et al. Abdominal actinomycosis: complication of endoscopic stenting in chronic pancreatitis? Endoscopy. 2001;33:1065-9.

30 Saad M, Moorman J. Images in clinical medicine. Actinomyces hepatic abscess with cutaneous fistula. N Engl J Med. 2005;353:e16.

31 Logan MN, Stanley PJ, Exley A, Gagg C, Farrell ID. Actinomycetes in pyogenic liver abscess. Eur J Clin Microbiol Infect Dis. 1989;8: 394-6.

32 Jermini-Gianinazzi I, Luethy R, Gubler J. An unusual case of hepatic abscess. Praxis. 2004; 93:1781-4.

33 Aslan A, Ayaz E, Inan I, Acar M. Isolated hepatic actinomycosis mimicking hepatocellular carcinoma: case report and review. Adv Dig Med. 2018;5(1-2):55-8.

34 Chen LW, Chang LC, Shie SS, Chien RN. Solitary actinomycotic abscesses of liver: report of two cases. Int J Clin Pract. 2006;60:104-7.

35 Ridha A, Oguejiofor N, Al-Abayechi S, Njoku E. Intra-abdominal actinomycosis mimicking malignant abdominal disease. Case Rep Infect Dis. 2017;2017:1972023.

36 Sahay S, McKelvy BJ. Actinomycosis presenting as recurrent hepatic abscess. Am J Med. 2017;130:e21-2.

37 Xing J, Rodriguez EF, Monaco SE, Pantanowitz L. Cytopathology of hepatobiliary-related actinomycosis. Acta Cytol. 2016;60:179-84.
38 Islam T, Athar MN, Athar MK, Usman MH, Misbah B. Hepatic actinomycosis with infiltration of the diaphragm and right lung: a case report. Can Respir J. 2005;12:336-7.

39 Mzoughi Z, Hfaiedh R, Ben Abid S, Miloudi $\mathrm{N}$, Marsaoui L, Arfa N, et al. Actinomycose hépatique a rare hepatic tumor: hepatic actinomycosis. Tunis Med. 2013;91:219-20.

40 Kothadia JP, Samant H, Olivera-Martinez M. Actinomycotic hepatic abscess mimicking liver tumor. Clin Gastroenterol Hepatol. 2018;16:e86.

41 Min KW, Paik SS, Han H, Jang KS. Education and imaging. Hepatobiliary and pancreatic: hepatic actinomycosis. J Gastroenterol Hepatol. 2012;27:844.

42 Kim HS, Park NH, Park KA, Kang SB. A case of pelvic actinomycosis with hepatic actinomycotic pseudotumor. Gynecol Obstet Invest. 2007;64(2):95-9.

43 White JE, Chase CW, Kelley JE, Brock WB, Clark MO. Inflammatory pseudotumor of the liver associated with extrahepatic infection. South Med J. 1997;90(1):23-9.

44 Emre A, Carilli S, Hazar H, Ince U, Calangu S. Hepatic involvement of disseminated actinomycosis. J Hep Bil Pancr Surg. 1997;4(3): 337-9.

$45 \mathrm{Yu}$ CY, Chang WC, Gao HW, Chao TY, Huang GS, Hsieh CB. Metastatic hepatic actinomycosis. Am J Med. 2010;123(9):e9-e11.

46 Hung-Wei C, Yang YS, Lin TY, Jung-Chung L, Feng-Yee C, Wang NC. Tubo-ovarian actinomycosis complicated with hepatic abscess. J Med Sci. 2010;30(6):261-4.

47 Sheth S, Fishman EK, Sanders R. Actinomycosis involving the liver. Computed tomography/ultrasound correlation. J Ultrasound Med. 1987;6(6):329-31.

48 Abid M, Amar MB, Feriani N, Damak Z, Cheikhrouhou H, Khalif M, et al. Actinomycose pelvienne pseudotumorale pelvic pseudotumoral actinomycosis: two cases. Rev Med Interne. 2010;31(3):232-5.

49 Ishiguro T, Takayanagi T, Ikarashi H. Multiple metastatic liver abscesses and intravenous thrombosis due to pelvic actinomycosis. Eur J Obstet Gynecol Reprod Biol. 2016;198:166-7.

50 Andersen AB, Ravn P, Kahn R, Rosted A, Philipsen EK. Hepatic actinomycosis. A case report. APMIS. 1999;107:225-30.

51 Ruutu P, Pentikäinen PJ, Larinkari U, Lempinen $\mathrm{M}$. Hepatic actinomycosis presenting as repeated cholestatic reactions. Scand J Infect Dis. 1982;14:235-8.

52 Shurbaji MS, Gupta PK, Newman MM. Hepatic actinomycosis diagnosed by fine needle aspiration. A case report. Acta Cytol. 1987;31: 751-5.

53 Granger JK, Houn HY. Diagnosis of hepatic actinomycosis by fine-needle aspiration. Diagn Cytopathol. 1991;7:95-7.

54 Golematis B, Hatzitheofilou C, Melissas J. Liver actinomycosis: a case report. Am J Gastroenterol. 1976;65:148. 
55 Sharma M, Briski LE, Khatib R. Hepatic actinomycosis: an overiew of salient features and outcome. Scand J Infect Dis. 2002;34:386-91.

56 Hayashi M, Asakuma M, Tsunemi S, Inoue Y, Shimizu T, Komeda K, et al. Surgical treatment for abdominal actinomycosis: a report of two cases. World J Gastrointest Surg. 2010; 2:405-8.

57 Ha YJ, An JH, Shim JH, Yu ES, Kim JJ, Ha TY, et al. A case of primary hepatic actinomycosis: an enigmatic inflammatory lesion of the liver. Clin Mol Hepatol. 2015;21:80-4.

58 Galindo JL, Fajardo E, Ojeda P, Carrillo JA. Abscesos hepáticos múltiples y empiema: una presentación inusual de actinomicosis. Infectio. 2017;21:61-4.

59 Sakaguchi T, Hashimoto D, Satoi S, Yamamoto T, Yamaki S, Sekimoto M. Hepatic actinomycosis after total pancreatectomy: a case report. Int J Surg Case Rep. 2021;85:106212.

60 Lange CM, Hofmann WP, Kriener S, Jacobi V, Welsch C, Just-Nuebling G, et al. Primary actinomycosis of the liver mimicking malignancy. Z Gastroenterol. 2009:1062-4.

61 Pheils MT, Reid DJ, Ross CF. Abdominal actinomycosis. Br J Surg. 1964;51:345-50.

62 Forgan-Smith JR, Mowat P, Strutton G. A report of actinomycosis involving the lung and liver. Med J Aust. 1989;150:153-5.

63 Uehara Y, Takahashi T, Yagoshi M, Shimoguchi K, Yanai M, Kumasaka K, et al. Liver abscess of Actinomyces israelii in a hemodialysis patient: case report and review of the literature. Intern Med. 2010;49:2017-20.

64 Lee JH, Kim HS, Kim JS, Lee DK, Lim JH. Hepatic actinomycosis with immunoglobulin G4-related liver disease: a case report. Medicine. 2018;97:e11146.

65 Roesler PJ Jr, Wills JS. Hepatic actinomycosis: CT features. J Comput Assist Tomogr. 1986; 10:335-7.

66 Chung JW, Bae YS, Lim JH, DongLee K, Yu JS. IgG4-related hepatic inflammatory pseudotumor complicated by actinomycosis during steroid therapy. J Korean Soc Radiol. 2019;80:351-8.

67 Nadal HM, Munoz M. Actinomycosis of the liver. Bol Asoc Med P R. 1965;57:225-9.

68 Brewer JH, Allen MJ. Actinomycosis of the gallbladder with liver abscess. South Med J. 1980;73:1070-2.

69 Serrano-Rios M, Navarro V, Fontan J, Oliva $\mathrm{H}$, Ramirez J. Isolated hepato-pancreatic actinomycosis. Report of a case stimulating an acute abdomen of fatal course. Digestion. 1969;2:262-71.

70 Mongiardo N, De Rienzo B, Zanchetta G, Lami G, Pellegrino F, Squadrini F. Primary hepatic actinomycosis. J Infect. 1986;12:65-9.
71 Riegert-Johnson DL, Sandhu N, Rajkumar SV, Patel R. Thrombotic thrombocytopenic purpura associated with a hepatic abscess due to Actinomyces turicensis. Clin Infect Dis. 2002;35:636-7.

72 Correa Bonito A, Mora-Guzmán I, GarcíaSanz I, di Martino M, Martín-Pérez E. Liver abscess after endoscopic retrograde cholangiopancreatography with presence of Actinomyces naeslundii. Cir Esp. 2017;95:51-2.

73 Jaqua NT, Smith AJ, Shin TT, Jahanmir J. Actinomyces naeslundii and Eikenella corrodens as rare causes of liver abscesses. BMJ Case Rep. 2013;2013:bcr2013009613.

74 Cavrić G, Nasabain K, Jurić K, Prkačin I, Bartolek Hamp D, Bogdanović Dvorščak M. Liver abscess caused by Actinomyces odontolyticus, Abiotrophia species, Haemophilus parainfluenzae, Streptococcus anginosus i Streptococcus intermedius: case report. Signa Vitae. 2015;10(Suppl 1):S72-3.

75 Chao CT, Liao CH, Lai CC, Hsueh PR. Liver abscess due to Actinomyces odontolyticus in an immunocompetent patient. Infection. 2011;39:77-9.

76 Ciria-Bru R, Naranjo-Torres A, Sánchez-Hidalgo JM, Briceño-Delgado J, López-Cillero P. Right hepatectomy due to hepatic actinomycosis. Cir Esp. 2008;83:327-8.

77 García-Corbeira P, Esteban-Moreno J. Liver abscess due to Actinomyces meyeri. Clin Infect Dis. 1994;18:491-2.

78 Lakshmana Kumar YC, Javherani R, Malini A, Prasad SR. Primary hepatic actinomycosis. Trans R Soc Trop Med Hyg. 2005;99:868-70.

79 Miyamoto MI, Fang FC. Pyogenic liver abscess involving Actinomyces: case report and review. Clin Infect Dis. 1993;16:303-9.

80 Murphy P, Mar WA, Allison D, Cornejo GA, Setty S, Giulianotti PC. Hepatic actinomycosis: a potential mimicker of malignancy. Radiol Case Rep. 2019;15:105-9.

81 Petrache D, Popescu GA. Successful switch to oral therapy with doxycycline in the case of an actinomycotic hepatic abscess. J Infect Dev Ctries. 2013;7:421-3.

82 Soardo G, Basan L, Intini S, Avellini C, Sechi LA. Elevated serum CA 19-9 in hepatic actinomycosis. Scand J Gastroenterol. 2005;40: 1372-3.

83 Sugano S, Matuda T, Suzuki T, Makino H, Iinuma $\mathrm{M}$, Ishii $\mathrm{K}$, et al. Hepatic actinomycosis: case report and review of the literature in Japan. J Gastroenterol. 1997;32:672-6.

84 Yang SS, Im YC. Severe abdominopelvic actinomycosis with colon perforation and hepatic involvement mimicking advanced sigmoid colon cancer with hepatic metastasis: a case study. BMC Surg. 2018;18:51.
85 Zeng QQ, Zheng XW, Wang QJ, Yu ZP, Zhang QY. Primary hepatic actinomycosis mimicking liver tumour. ANZ J Surg. 2018; 88:E629-30.

86 Felekouras E, Menenakos C, Griniatsos J, Deladetsima I, Kalaxanisi N, Nikiteas N, et al. Liver resection in cases of isolated hepatic actinomycosis: case report and review of the literature. Scand J Infect Dis. 2004;36:535-8.

87 Biggs JSG. Actinomycosis of the liver: a report of two cases. Med J Aust. 1960;2(24):939-40.

88 Cheng YF, Hung CF, Liu YH, Ng KK, Tsai CC. Hepatic actinomycosis with portal vein occlusion. Gastrointest Radiol. 1989;14:26870.

89 Lu CL, Hwang SJ, Chang CF, Wu JC, Chiang $\mathrm{H}$, Chiang $\mathrm{JH}$, et al. Hepatic actinomycosis with portal vein thrombosis mimicking hepatocellular carcinoma: a case report. Zhonghua Yi Xue Za Zhi. 1993;51:381-5.

90 Nazarian LN, Spencer JA, Mitchell DG. Multiple actinomycotic liver abscesses: MRI appearances with etiology suggested by abdominal radiography. Case report. Clin Imaging. 1994;18:119-22.

91 Nemcek AA Jr, Vogelzang RL. SIR 2004 film panel case: hepatic actinomycosis from pelvic inflammatory disease causing portal vein thrombosis. J Vasc Interv Radiol. 2004;15: 1363-5.

92 Sakaguchi Y, Isowa N, Nakazaki H, Takeda K, Tokuyasu H, Saitoh Y, et al. Acute cardiac tamponade caused by the extension of multiple hepatic actinomycotic abscesses. Intern Med. 2012;51:305-8.

93 Olds KL, Gilbert JD, Byard RW. Actinomyces in forensic practice. Am J Forensic Med Pathol. 2021;42(2):191-3.

94 Chandarlapaty SK, Dusol M Jr, Edwards R, Pereiras R Jr, Clark R, Schiff ER. 67Gallium accumulation in hepatic actinomycosis. Gastroenterology. 1975;69:752-5.

95 Powell G, Mangalika M. Thoraco-pulmonary and hepatic actinomycosis: an autopsy report. BMJ Case Rep. 2011;2011:bcr0920114831.

96 van Marion WF, Thompson J, Mouton RP, Ottenhoff TM, van Furth R. Successful single antibiotic therapy in Actinomyces septicemia and liver abscess. Infection. 1982;10:287-9.

97 Seo JY, Yeom JS, Ko KS. Actinomyces cardiffensis septicemia: a case report. Diagn Microbiol Infect Dis. 2012;73:86-8.

98 Chegini Z, Didehdar M, Tabaeian SP, Khoshbayan A, Shariati A. A systematic review of case reports of hepatic actinomycosis. Orphanet J Rare Dis. 2021;16(1):192. 